\title{
EVALUATION OF QUALITY OF LIFE-RELATED TO ORAL HEALTH AFTER DIFFERENT PROSTHETIC TREATMENTS IN EDENTULISM PATIENTS
}

\author{
Zeynep Basagaoglu Demirekin ${ }^{1 凹}$ (D), Elif Erten ${ }^{2} \square$ (iD) \\ ${ }^{1}$ P. hd DDS, Suleyman Demirel University Faculty of Dentistry, Department of Prosthodontics, Isparta, Turkey \\ 2 Suleyman Demirel University Faculty of Dentistry, Department of Prosthodontics, Isparta, Turkey
}

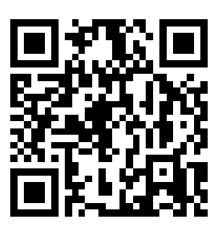

Received 22 January 2022

Accepted 26 February 2022

Published 07 March 2022

\section{Corresponding Author}

Zeynep Basagaoglu Demirekin, dtzeynepbasagaoglu@yahoo.com.tr

DOI

10.29121/granthaalayah.v10.i2.2022 .4510

Funding: This research received no specific grant from any funding agency in the public, commercial, or not-for-profit sectors.

Copyright: (C) 2022 The Author(s). This is an open access article distributed under the terms of the Creative Commons Attribution License, which permits unrestricted use, distribution, and reproduction in any medium, provided the original author and source are credited.

\section{ABSTRACT}

Background: The impact of edentulism on oral health status is an important public health issue. Conventional complete dentures, implant-supported removable dentures and implant-supported fixed dentures are evidence-based treatment IRPtions in the treatment of complete edentulism. Quality of life may be compromised due to various reasons such as functional problems, diseases, nutritional deficiency, physiological and psychosocial problems in individuals using prostheses.

Objectives: Our aim in this study is to evaluate patient satisfaction of completely edentulous patients treated with conventional complete dentures, implant-supported removable dentures and implant-supported fixed dentures, oral health-related quality of life and to compare the effects on quality of life.

Methods: In this study, total of 140 patients involved, 49 female and 91 males, aged between 40 and 90 who were completely edentulous and treated at least 6 months ago in the Prosthetic Dentistry Clinic.

Patients were divided into 3 groups as conventional complete denture (CD), implant retained overdenture (IRP) and implant supported fixed prosthesis (ISFP). By Oral Health Impact Profile (OHIP-14), Oral Health-Related Quality of Life-United Kingdom (OHQoL-UK) questionnaires oral health-related quality of life was measured analyzed and obtained parameters were compared.

Results: When all findings were evaluated, the oral health-related quality of life of the group treated with implant-supported fixed prosthesis were found to be higher than the conventional complete denture and implant-supported fixed prosthesis group. In addition, it was determined that implant-supported fixed and removable treatments had positive effects on patient satisfaction, quality of life compared to conventional complete denture treatment.

Conclusions: Support from dental implants while making a prosthetic treatment plan in edentulous patients will contribute positively to the stability and retention of the prosthesis. This will increase the quality of life of the person by supporting patient satisfaction, adaptation to the prosthesis and nutrition.

Keywords: Complete Edentulism, Oral Health, Life Quality

\author{
ABBREVIATION \\ OHQoL: Oral health-related quality of life \\ CD: Complete dentures \\ IRP: Implant retained overdentures \\ ISFP: Implant supported fixed prosthesis \\ OHIP-14: Oral Health Impact Profile-14 \\ OHQoL-UK: Oral Health-Related Quality of Life-United Kingdom
}




\section{INTRODUCTION}

'Edentulism' is one of the critical markers of oral and dental health; a Complete edentulous state is defined as the loss of the integrity of the chewing system accompanied by negative functional and aesthetic deficiencies Ferro et al. (2017). Complete tooth loss is a frequently encountered situation in individuals in the advanced age group. It has a significant impact on the patient's quality of life, as it can adversely affect the person's physiological, biological, social, and psychological state Ozdemir et al. (2006). Studies show that the aging trend of the world pIRPulation is increasing. According to the research conducted by the World Health Organization (WHO) in 2005, the number of peIRPle aged 60 and over was determined to be 672 million. It is estimated that this number may reach approximately 2 billion in 2050 Nations (2005). Complete edentulism; can cause physical, psychological, and social limitations, adverse effects on diet and food choice, functional and sensory changes in the oral mucosa, systemic diseases, and a decrease in the general and oral health-related quality of life (OHQOL) levels of older adults Kroll et al. (2018), Locker (1988), Dogan and Gokalp (2012). It is thought that the documents, which combine the methods used to measure patient satisfaction and the functional, social, and psychological effects of tooth loss, can provide important information about the results of prosthetic treatment Heydecke et al. (2004).

There is evidence that edentulism is closely related to sociodemographic and behavioral factors. It is necessary to maintain functional dentition and balanced nutrition in the elderly. Rehabilitation of partial or total edentulism with an apprIRPriate prosthetic treatment IRPtion may be recommended. Thus, the effectiveness of chewing function can be restored, and the balanced and adequate consumption of essential nutrients required for the body can be facilitated. Aesthetics and phonation can also be corrected with effective prosthetic treatment. All these positive effects will affect the psychology and social life of the elderly positively Köse et al. (2013). Studies show different effects of prosthetic treatment on oral health-related quality of life. Patients who switch from removable partial dentures to fixed tooth-supported or implant-supported prostheses experience significant improvements in their quality of life as the stability of the prosthesis increases Bassetti et al. (2016). Our study aims to evaluate the effect of prosthesis groups with extra stability, such as conventional complete dentures, implant-

supported overdenture prosthesis, and implant-supported fixed prosthesis applied to edentulous patients, on the oral health-related quality of life of the patients.

\section{MATERIALS AND METHODS 2.1. DETERMINATION OF SAMPLE SIZE}

While determining the sample size, it is apprIRPriate to select individuals 5-10 times the total number of items in the questionnaire. Therefore, in line with this information in the literature; Based on the Oral Health-Related Quality of Life (OHQoL-UK) scale, which includes 16 questions, at least 5 times (16 items x 5=80) individuals were included for reliability and validity analyses. 


\subsection{QUESTIONNAIRES}

Demographic information, including age, gender, education level, smoking, income level of the participants, and general health status such as current systemic diseases, were asked. Oral Health Impact Profile-14 (OHIP-14) and Oral HealthRelated Quality of Life -UK (OHQoL- UK) questionnaires were administered to the participants to measure their oral health-related quality of life Slade (1997), McGrath and Bedi (2001). Turkish versions of OHIP-14 and OHQoL-UK, which were previously determined to be valid and reliable, were used in this study Mumcu et al. (2006).

\subsection{PATIENT SELECTION AND METHOD}

Ethics committee approval of the study was received from Süleyman Demirel University Faculty of Medicine Clinical Research Ethics Committee. Research: The study was conducted with patients who completed their prosthetic treatment and used their prostheses for at least six months in the Department of Prosthetic Dentistry of the Faculty of Dentistry of Süleyman Demirel University.

Patients who came to their appointments were informed about the purpose of applying the questionnaires. The patients were asked to answer the questionnaire questions by a single researcher with unambiguous answers. One hundred forty peIRPle who agreed to participate in the study and read and signed informed voluntary consent forms were included. The patients are in 3 groups.

- Group 1: 40 patients treated with conventional complete dentures (CD) in the lower and upper jaws,

- Group 2: 50 patients treated with a complete maxillary denture, a lower jaw with two implant- supported locater-retained overdenture prostheses (IRP),

- Group 3: The mandible and maxilla were analysed as 50 patients treated with the whole arch implant-supported fixed prosthesis (ISFP).

\subsection{STATISTICAL ANALYSIS}

The data obtained in the study were analysed using SPSS 25.0 (Statistical Package for Social Sciences) and AMOS 21 program. Descriptive statistical methods (number, percentage, mean, standard deviation, minimum and maximum) were used while evaluating the data. In addition, the normal distribution of the data used was tested with the Shapiro Wilk and Kolmogorov-Smirnov test.

Parametric tests were used for normally distributed measurements, and nonparametric tests were used for non-normally distributed measurements. For quantitative data, Mann Whitney $U$ was used to compare the means of two independent groups that did not have a normal distribution, Kruskal Wallis analysis was used to compare the mean rank of more than two groups that did not have a normal distribution, and ANOVA analysis of variance was used to compare the means in groups with normal distribution. Bonferroni analysis was performed to determine the difference between which groups for the results found to be statistically significant between the groups. The questionnaire's reliability was tested with Cronbach Alpha reliability analysis, and Confirmatory Factor Analysis (CFA) was performed. Spearman correlation analysis was performed to measure the 
relationship between quantitative variables used in the study, and Chi-square analysis was performed for categorical variables, and the results were interpreted.

\section{RESULTS}

Participants were divided into 3 study groups according to the types of prostheses they used. Group $1(n=40) 28.6 \%$ patients using traditional mandibular and maxillary full dentures (CD), Group $2(\mathrm{n}=50) 35.7 \%$ maxillary full dentures, mandibular 2 implant-supported locater-retained overdenture prosthesis (IRP) patients, Group $3(n=50) 35.7 \%$ were patients using lower and upper jaw whole arch implant-supported fixed prosthesis (ISFP).

A total of 140 fully edentulous patients, 49 (35\%) female, and 91 (65\%) males, with an average age of $62.60 \pm 9.06$ years, ranging from 40 to 90 years, were included in our study.

\begin{tabular}{|c|c|c|c|c|}
\hline & & CD & IRP & ISFP \\
\hline GENDER & Men & $27 / 67.5$ & $25 / 50.0$ & $39 / 78.0$ \\
\hline \multirow[t]{2}{*}{ (n / \%) } & Women & $13 / 32.5$ & $25 / 50.0$ & $11 / 22.0$ \\
\hline & Age (Mean \pm SD) & $66.13 \pm 8.59$ & $64.50 \pm 8.59$ & $57.88 \pm 7.98$ \\
\hline
\end{tabular}

Table 2 Comparison of the Oral Health Impact Profile Scale (OHIP-14) according to the groups

\begin{tabular}{cccccccc}
\hline & N & AVERAGE & $\begin{array}{c}\text { STANDARD } \\
\text { DEVIATION }\end{array}$ & $\begin{array}{c}\text { AVERAGE2 } \\
\text { RANK }\end{array}$ & X2 & P & BONFERRONI \\
\hline OHIP-14 & & & \\
\hline CD & $\mathbf{4 0}$ & 27,38 & 10,64 & 98,69 & 37,199 & $0,000^{*}$ & $3<2$ \\
\hline IRP & $\mathbf{5 0}$ & 21,78 & 8,75 & 71,58 & & & $3<1$ \\
\hline IDSP & $\mathbf{5 0}$ & 16,84 & 3,25 & 46,60 & & & $2<1$ \\
\hline
\end{tabular}

According to the results of the analysis, it was found that there was a statistically significant difference between the CD, IRP, and ISFP groups of the participants, between the mean ranks of the scores they got from OHIP-14 (X2 $=37.199, \mathrm{p}=0.000<0.05)$. Bonferroni analysis was performed to detect the difference between the groups. According to the analysis results, it was seen that all groups caused the difference. Accordingly, it can be said that CD, IRP, and ISFP groups are the highest in terms of the scores obtained from OHIP-14. When the values obtained from the OHIP-14 sub- dimensions are examined, the ISFP group shows the highest satisfaction. Only in the Psychological Discomfort sub-dimension no statistically significant result was reached between the groups ( $X 2=5.011, p=0.082>0.05)$.

\begin{tabular}{cccccccr}
\hline \multicolumn{7}{c}{ Table 3} & Comparison of Oral and Dental Health-Related Quality of Life-UK (OHQoL) by groups \\
\hline & N & AVERAGE & $\begin{array}{c}\text { STANDARD } \\
\text { DEVIATION }\end{array}$ & $\begin{array}{c}\text { AVERAGE } \\
\text { RANK }\end{array}$ & X2 & P & BONFERRONI \\
\hline CD & 40 & 58,75 & 12,08 & 51,68 & 16,444 & $0,000^{*}$ & $1<3$ \\
\hline IRP & 50 & 63,62 & 11,25 & 69,57 & & & \\
İDSP & 50 & 67,60 & 10,81 & 86,49 & & & \\
\end{tabular}




\begin{tabular}{|c|c|c|c|c|c|c|}
\hline & & $\begin{array}{c}\text { OHIO- } \\
\text { UK }\end{array}$ & $\begin{array}{c}\text { SYMP } \\
\text { TOM }\end{array}$ & $\begin{array}{c}\text { PHYSICALSTA } \\
\text { TUS }\end{array}$ & $\begin{array}{c}\text { PSYCHOLOGICAL } \\
\text { STATUS }\end{array}$ & $\begin{array}{l}\text { SOCIAL } \\
\text { STATUS }\end{array}$ \\
\hline \multirow[t]{2}{*}{ ОНIP-14 } & r & $-0,701$ & $-0,667$ & $-0,561$ & $-0,667$ & $-0,652$ \\
\hline & $\mathrm{p}$ & $0,000^{*}$ & $0,000^{*}$ & $0,000^{*}$ & $0,000^{*}$ & $0,000^{*}$ \\
\hline \multirow{2}{*}{$\begin{array}{l}\text { FUNCTIONAL } \\
\text { LIMITATION }\end{array}$} & $\mathrm{r}$ & $-0,504$ & $-0,489$ & $-0,474$ & $-0,486$ & $-0,438$ \\
\hline & $\mathrm{p}$ & $0,000^{*}$ & $0,000^{*}$ & $0,000^{*}$ & $0,000^{*}$ & $0,000^{*}$ \\
\hline \multirow{2}{*}{$\begin{array}{l}\text { PHYSICAL } \\
\text { PAIN }\end{array}$} & $r$ & $-0,603$ & $-0,576$ & $-0,484$ & $-0,578$ & $-0,573$ \\
\hline & $\mathrm{p}$ & $0,000 *$ & $0,000^{*}$ & $0,000^{*}$ & $0,000^{*}$ & $0,000^{*}$ \\
\hline \multirow{2}{*}{$\begin{array}{l}\text { PSYCHOLOGIC } \\
\text { AL DISEASE }\end{array}$} & $\mathrm{r}$ & $-0,535$ & $-0,526$ & $-0,484$ & $-0,515$ & $-0,468$ \\
\hline & $\mathrm{p}$ & $0,000^{*}$ & $0,000^{*}$ & $0,000^{*}$ & $0,000^{*}$ & $0,000^{*}$ \\
\hline \multirow{2}{*}{$\begin{array}{l}\text { PHYSICAL } \\
\text { DISABILITY }\end{array}$} & $\mathrm{r}$ & $-0,556$ & $-0,565$ & $-0,453$ & $-0,521$ & $-0,540$ \\
\hline & $\mathrm{p}$ & $0,000 *$ & $0,000^{*}$ & $0,000^{*}$ & $0,000^{*}$ & $0,000^{*}$ \\
\hline \multirow{2}{*}{$\begin{array}{l}\text { PSİKOLOJİK } \\
\text { YETERSIZLIKK }\end{array}$} & $r$ & $-0,514$ & $-0,410$ & $-0,413$ & $-0,481$ & $-0,513$ \\
\hline & $\mathrm{p}$ & $0,000^{*}$ & $0,000^{*}$ & $0,000^{*}$ & $0,000^{*}$ & $0,000^{*}$ \\
\hline \multirow{3}{*}{$\begin{array}{c}\text { SOCIAL } \\
\text { DEFICIENCY }\end{array}$} & $\mathrm{r}$ & $-0,522$ & $-0,494$ & $-0,367$ & $-0,500$ & $-0,506$ \\
\hline & $\mathrm{p}$ & $0,000^{*}$ & $0,000^{*}$ & $0,000^{*}$ & $0,000^{*}$ & $0,000^{*}$ \\
\hline & r & -316 & $-0,301$ & $-0,223$ & $-0,301$ & $-0,310$ \\
\hline HANDICAP & $\mathrm{p}$ & $0,000^{*}$ & $0,000^{*}$ & $0,008^{*}$ & $0,000^{*}$ & $0,000^{*}$ \\
\hline
\end{tabular}

According to the analysis results, it was determined that there was a statistically significant negative correlation between the OHIP-14 and OHQoL-UK scores of the participants $(r=-701, p=0.000<0.05)$.

\section{DISCUSSION}

WHO has defined quality of life as a health-related term Organization (2017) Although this term is used as an indicator to evaluate oral health, especially in the elderly, it evaluates the individual's oral health, function, and emotional well-being Tsakos et al. (2006). Patients cannot adapt to every successful prosthetic treatment applied in some cases. As a result, comfort in eating and speaking at a sufficient level cannot be provided Gift and Redford (1992), Heydecke et al. (2003)

Determining patient satisfaction provides a detailed analysis of social, psychological, and functional effects on the success of applied prosthetic rehabilitation. Researchers stated that, unlike traditional clinical evaluation methods, patients should evaluate treatment success individually Feine et al. (1998), Slade and Spencer (1994)

Various scales have been develIRPed to investigate the quality of life-related to oral health and to determine the level of this quality. When the studies in which these scales were applied are examined, the Oral Health Impact Profile (OHIP-14) and the Oral Health-Related Quality of Life-UK version (OHQoL-UK) are among the most widely applied scales Slade and Spencer (1994), Geçkili et al. (2010), McGrath 
and Bedi (2003), Hegarty et al. (2002) In our study, oral health- related quality of life of patients who underwent conventional complete dentures, implant- supported removable dentures, and implant-supported fixed dentures in the rehabilitation of edentulous patients was evaluated with the OHIP-14 and OHQoL-UK scales.

Our study evaluated the reliability coefficients and confirmatory factor analyses of the OHIP-14 and OHQoL-UK scales and sub-dimensions. In our study, the reliability (Cronbach's alpha) value of the OHIP-14 Scale was determined as 0.894 . According to Confirmatory Factor Analysis, it was determined that the structural equation model result of the Scale was significant at the $\mathrm{p}=0.000$ level, and 14 items and 7 sub-dimensions of the OHIP-14 Scale were related to the scale structure. The reliability (Cronbach's alpha) value of the OHQoL-UK scale was 0.960 . The Cronbach's Alpha values of both scales and their sub-dimensions are greater than 0.40 , indicating that the scales used are reliable. According to the Confirmatory Factor analysis, it was determined that the structural equation model result for both scales was significant at the $\mathrm{p}=0.000$ level, 14 items and 7 sub- dimensions of the OHIP-14 Scale, and 16 items and 4 sub-dimensions of the OHQoL-UK scale were related to the scale structures.

Complete edentulism is a condition defined as the loss of all permanent teeth in the lower and upper jaws. Toothlessness affects various factors such as speech, appearance, decrease in eating and chewing quality, nutritional deficiency, and decrease in quality of life. According to the WHO criteria, this condition is classified as a disability Organization (2007).

Although the incidence of complete edentulism has decreased in recent years with improving oral health, it is still a worldwide concern. With the prolongation of life expectancy, toothlessness, which is one of the more common problems in advanced age groups, negatively affects the person's aesthetic, psychological, nutritional, and functional conditions McGrath and Bedi (2003). This situation affects the general health and the oral and dental health of the person and causes a decrease in the quality of life of the individual Locker and Allen (2007), Åstrøm et al. (2006) Adverse effects on oral and dental health are associated with low quality of life Brennan et al. (2008). To solve these problems, it is aimed to increase the physical, psychological, and social well-being of patients with complete dentures, implant-supported removable and implant-supported fixed prostheses for edentulous patients Locker et al. (2002), Preciado et al. (2013), Emami et al. (2015)

Conventional treatment of complete edentulism is performed with full dentures Awad et al. (2003). Traditional complete dentures have been preferred for years because of their low cost and lack of surgical procedures required for implantsupported prostheses Walton and MacEntee (2005). In the study of Chetri et al. (2020), with 80 patients aged between 43 and 90 years, conventional complete dentures were applied to edentulous patients, and the change in OHIP scale and OHQoL was examined. According to the study results, the functional use of complete dentures increases OHQoL Chetri et al. (2020). Consequently, tooth loss may be associated with low levels of OHQoL Gerritsen et al. (2010). Rehabilitation of peIRPle's functional, aesthetic, and chewing functions is provided with complete dentures. In mandibular conventional full dentures, it may be challenging to provide adequate stabilization and retention due to resorptions in the alveolar bone depending on factors such as the shape and height of the alveolar crest. However, limitations in function and phonation negatively affect patients psychologically, leading the patient and physician to different treatment IRPtions Feine et al. (2002). 
In the study of Fontijn-Tekamp et al. (2001), patients using complete dentures and patients using implant-supported overdenture prostheses were compared, and $88 \%$ of the complete denture group

stated that they felt pain during biting and chewing function. The rate of those who felt pain in implant-supported prostheses was reported as $13 \%$ FontijnTekamp et al. (2001).

This has a negative impact on the person's social status. The movement caused by the prosthesis reduces patient comfort. In some cases, patients may avoid the social environment entirely or may have to adapt their food choices in accordance with their prostheses Hyland et al. (2009). As a result, malnutrition problem arises. This situation reduces patients' quality of life and satisfaction using traditional complete dentures.

With the widespread use of endosseous implants in clinical dentistry, the McGill consensus was accepted to solve the prosthesis stabilization problem, especially in the lower jaw Feine et al. (2002). High retention, stabilization, aesthetics, and ease of use in these patients could be achieved with implant- supported overdenture prostheses in the mandible. To support the McGill consensus decision, the York joint statement was published in 2009 Thomason et al. (2009).

In their study by Bassetti et al. (2016), examining traditional complete denture, fixed denture, and removable partial denture groups, they reported that clinically significant improvements in oral health-related quality of life occur with the increase in rigidity in the prosthetic treatment procedure Bassetti et al. (2016).

IDPs take up less space in volume compared to IRP. The fact that IDPs do not entirely cover the palatal region may help reduce discomfort by making the prosthesis be tolerated more quickly in some patients De et al. (2000). However, these prostheses are a treatment IRPtion that requires longer treatment processes and surgical procedures and higher treatment costs (158). However, it has been reported that patients are more successful in maintaining oral hygiene with IRP, and lip support can be provided more effectively with IRP in terms of aesthetics Heydecke et al. (2003).

The OHIP-14 and OHQoL-UK scales, which evaluate oral health-related quality of life, were administered to the participants in our study. According to the findings, the oral health-related quality of life of the IRP group was found to be significantly higher than that of the CD group $(\mathrm{p}<0.05)$. In addition, a statistically significant difference was observed when the IRP group was compared with the CD group according to the scores they got from the Physical Disability and Social Disability sub-dimensions $(\mathrm{p}<0.05)$.

When the CD, IRP, and ISFP groups of oral health-related quality of life were evaluated according to the total scores of the OHIP-14 Scale from CD and the Physical Disability and Social Disability sub- dimensions, significant results were obtained in all groups. With OHIP-14, the scores from the highest to the lowest in Physical Disability and Social Disability sub-dimensions are CD, IRP, and ISFP. As a result of the findings, the group with the lowest oral and dental health-related quality of life in OHIP- 14 and Physical Disability and Social Disability subdimensions is the CD group, with the highest oral and dental health-related quality life in the ISFP group. It has been stated that implant-supported fixed prostheses, which are among the treatment IRPtions of edentulous patients, will be the preferred treatment IRPtion. They are more stable than removable prostheses if many implants are placed and clinical criteria are met Sadowsky (1997). 
According to the results of randomized crossover studies with patients using mandibular implant- supported dentures, no significant difference was found in patient satisfaction with mandibular

implant-supported overdenture and fixed dentures De et al. (1994) . In Elsyad (2016) study, oral health- related quality of life was evaluated with OHIP-14 inpatient groups using complete dentures, implant-supported fixed dentures, and bar-supported overdenture prostheses. According to the study results, OHQoL was determined as patients using complete denture, overdenture prosthesis, and patients using an implant-supported fixed prosthesis, respectively, from lowest to highest.

Significant results were achieved in all sub-dimensions of OHIP-14. The complete denture group showed a lower oral health-related quality of life score than the implant-supported fixed denture group. No significant difference was observed in the implant-supported fixed prosthesis group and the group using a barsupported overdenture prosthesis Elsyad (2016).

In the study by Brennan et al. (2010), the oral and dental health-related quality of life of 62 patients in the IRP and ISFP treatment group was evaluated with the OHIP-14 Scale. The findings concluded that the implant-supported overdenture group had higher satisfaction in all sub-dimensions of OHIP- 14 compared to complete dentures. In the ISFP group, patient satisfaction with aesthetics was higher than in the IRP group. In addition, OHRQoL scores for chewing capacity and general satisfaction in the ISFP group were found to be higher in all 7 sub-dimensions, but statistically significant was only achieved in the psychological disability subdimension Brennan et al. (2010).

In the study performed by Cakir et al. (2014), OHIP-14, OHQoL-UK, and SF-36 questionnaires were applied to a total of 116 patients who were treated with an implant-supported overdenture prosthesis, implant-supported fixed denture, conventional complete denture, and traditional partial denture, both before and after treatment. Oral health and general quality of life were evaluated. The findings concluded that the implant-supported overdenture prosthesis group improved OHQoL statistically significantly more than the other treatment groups. As a result, this treatment also positively affected the overall quality of life. In addition, when the mean scores of the oral health- related quality of life questionnaires in toothless arches before and after prosthetic treatment were examined, it was seen that the lowest values were in the implant-supported fixed prosthesis group, and the individuals in this group were higher in terms of adaptation and satisfaction with the implant-supported prosthesis Cakir et al. (2014). Our findings in the study are consistent with the studies of Brennan et al. (2010), Elsyad (2016), and Cakir et al. (2014), Elsyad (2016), Brennan et al. (2010), Cakir et al. (2014)

\section{CONCLUSION}

The results and recommendations obtained in our study, which evaluated the oral health-related quality of life, nutritional status, and the relationships between CD, IRP, and ISFP treatments in edentulous patients, are listed below.

According to the OHIP-14 questionnaire scores, the CD group reported a lower level of OHQoL than the other groups. In comparison, the ISFP group reported a higher level of OHQoL than the other groups. There is a statistically significant difference between the groups. It is thought that the low level of OHQoL in the CD group compared to the other groups affects the person negatively socially and 
psychologically as a result of the inadequacy of stability and retention in complete mandibular dentures.

The OHQoL-UK questionnaire scores were lower in the CD group than in the ISFP group, and there is a statistically significant difference between the groups. It is thought that the low level of OHQoL in

the CD group compared to the other groups affects the person negatively socially and psychologically as a result of the inadequacy of stability and retention in complete mandibular dentures.

Quality of life questionnaires was found to be compatible with each other. It was observed that the adaptation and satisfaction to the 2 implant-supported overdenture prostheses and implant- supported fixed prostheses applied to the lower jaw were higher than the CD group.

\section{ACKNOWLEDGEMENTS}

The authors thank Dr. Aylin Göçoğlu, Department of Statistics, Dokuz Eylul University Turkey for help with the statistical analyses.

\section{AUTHORS' CONTRIBUTIONS}

Elif Erten: Conceptualization, Data curation, Formal analysis, Project administration, Resources,Writing-original draft, Writing-review \& editing

Zeynep Basagaoglu Demirekin: Data curation, Formal analysis, Project administration,Resources, Writing-original draft, Writing-review \& editing)

\section{AVAILABILITY OF DATA AND MATERIALS}

The data that support the findings of this study are available from the corresponding author uponreasonable request.

\section{DECLARATIONS}

\section{Ethics approval and Consent for publication}

The ethical conduct of this study was approved by the School of Medicine Ethics Committee, Süleyman Demirel University (18.09.2020/275). The participants signed a written informed consent form following the Helsinki Declaration of the World Medical Association

\section{REFERENCES}

Awad MA, Lund JP, Shapiro SH, Locker D, Klemetti E, Chehade A, et al. (2003) Oral health status and treatment satisfaction with mandibular implant overdentures and conventional dentures : à randomized clinical trial in a senior pIRPulation. International Journal of Prosthodontics. ;16(4). Retrieved 
\%26profile\%3dehost $\% 26$ scope\%3dsite\%26authtype\%3dcrawler\%26jrnl \%3d08932174\%26AN\%3d36909223

Bassetti RG, Enkling N, Mericske-Stern RD. (2016) Are there differences in the changes in oral- health-related quality of life (OHRQoL) depending on the type (rigidity) of prosthetic treatment? Quintessence internationale. ;47(9) :749-57

Brennan DS, Spencer AJ, Roberts-Thomson KF. (2008) Tooth loss, chewing ability and quality of life. Quality of Life Research.;17(2) :227-35. Retrieved from https://doi.org/10.1007/s11136-007-9293-2

Brennan M, Houston F, O'Sullivan M, O'Connell B. (2010) Patient satisfaction and oral health-related quality of life outcomes of implant overdentures and fixed complete dentures. International Journal of Oral Maxillofacial Implants. $\quad$;25(4) :791-800. $\quad$ Retrieved from https://web.s.ebscohost.com/abstract?direct=true\&profile=ehost\&scope= site\&authtype $=$ crawler\&jrnl=08822786\&AN=52586286\&h=JwBZ7RPV0w \%2bGPpmBrESlz5NodZma3SiAXmJ\%2fQ7m\%2fst8LKQiSFkGUA0C4CS8lp cAMcZJSXBL5rQDKuquDGmrfPQ\%3d\%3d\&crl=c\&resultNs=AdminWebAut h\&resultLocal=ErrCrlNotAuth\&crlhashurl=login.aspx $\% 3$ fdirect $\% 3 d$ true $\%$ 26profile\%3dehost\%26scope\%3dsite\%26authtype\%3dcrawler\%26jrnl\% 3d08822786\%26AN\%3d52586286

Cakir O, Kazancioglu HO, Celik G, Deger S, Ak G. (2014) Evaluation of the efficacy of mandibular conventional and implant prostheses in à group of Turkish patients : à quality of life study. Journal of Prosthodontics. ;23(5) :390-6 Retrieved from https://doi.org/10.1111/jopr.12120

Carlsson G, Omar R. (2010) The future of complete dentures in oral rehabilitation: A critical review. Journal of Oral Rehabilitation. ;37(2) :143-56. Retrieved from https://doi.org/10.1111/j.1365-2842.2009.02039.x

Chetri S, Rathi A, Mehta P, Khadka R. (2020) Assessment of Oral Health Related Quality of Life in Completely Edentulous Patients after Prosthodontic Rehabilitation at Noble Medical College and Teaching Hospital, Biratnagar. Birat Journal of Health Sciences. ;5(1) :886-90. Retrieved from https://doi.org/10.3126/bjhs.v5i1.29603

De Albuquerque RF, Lund JP, Tang L, Larivée J, De Grandmont P, Gauthier G, et al. (2000) Within- subject comparison of maxillary long-bar implant-retained prostheses with and without palatal coverage : patient-based outcomes. Clinical Oral Implants Research. ;11(6) :555- 65. Retrieved from https://doi.org/10.1034/j.1600-0501.2000.011006555.x

De Grandmont P, Feine J, Tache R, Boudrias P, Donohue W, Tanguay R, et al. (1994) Within-subject comparisons of implant-supported mandibular prostheses : psychometric evaluation. Journal of Dental Research. ;73(5) :1096-104. Retrieved from https://doi.org/10.1177/00220345940730051201

Dogan BG, Gokalp S. (2012) Tooth loss and edentulism in the Turkish elderly. Archives of Gerontology and Geriatrics. ;54(2) : e162-e6. Retrieved from https://doi.org/10.1016/j.archger.2012.01.003

Elsyad MA. (2016) Patient satisfaction and prosthetic aspects with mini-implants retained mandibular overdentures. A 5-year prospective study. Clinical Oral Implants Research. ;27(7) :926-33. Retrieved from https://doi.org/10.1111/clr.12660

Emami E, de Souza RF, Bernier J, Rompré P, Feine JS. (2015) Patient perceptions of the mandibular three-implant overdenture : à practice-based study. Clinical 


$\begin{array}{llllll}\text { Oral Implants } & \text { Research. ;26(6) } & \text { :639-43. } & \text { Retrieved } & \text { from } \\ \text { https://doi.org/10.1111/clr.12351 } & & & \end{array}$

Feine J, Carlsson G, Awad M, Chehade A, Duncan W, Gizani S, et al. (2002) The McGill consensus statement on overdentures. Mandibular two-implant overdentures as first choice standard of care for edentulous patients. Gerodontology. $\quad ; 19(1) \quad$ :3-4. Retrieved from https://doi.org/10.1111/j.1741-2358.2002.00003.x

Feine JS, Awad MA, Lund JP. (1998) The impact of patient preference on the design and interpretation of clinical trials. Community Dentistry Oral Epidemiology. ;26(1) :70-4. Retrieved from https://doi.org/10.1111/j.1600-0528.1998.tb02086.x

Ferro KJ, Morgano SM, Driscoll CF, Freilich MA, Guckes AD, Knoernschild KL, et al. (2017) The Glossary of Prosthodontic Terms. The Journal of Prosthetic Dentistry. ;117(5S) : e12-e34.

Fontijn-Tekamp F, Slagter AP, Van't Hof MA, Kalk W, Jansen JA. (2001) Pain and instability during biting with mandibular implant-retained overdentures. Clinical Oral Implants Research. ;12(1) :46-51. Retrieved from https://doi.org/10.1034/j.1600-0501.2001.012001046.x

Gerritsen AE, Allen PF, Witter DJ, Bronkhorst EM, Creugers NH. (2010) Tooth loss and oral health- related quality of life : à systematic review and metaanalysis. Health Quality of Life Outcomes. ;8(1) :1-11. Retrieved from https://doi.org/10.1186/1477-7525-8-126

Geçkili O, Bural C, Bilmenoğlu Ç. (2010) İmplant destekli tam protezlerde kullanılan tutucu sistemler. Ege Üniversitesi Dişhekimliği Fakültesi Dergisi. ;31(1) :918. Retrieved from https://doi.org/10.5505/eudfd.2010.24865

Gift HC, Redford M. (1992) Oral health and the quality of life. Clinics in Geriatric Medicine. ;8(3) :673-84. Retrieved from https://doi.org/10.1016/S07490690(18)30471-3

Hegarty A, McGrath C, Hodgson T, Porter S. (2002) Patient-centred outcome measures in oral medicine : are they valid and reliable ? International Journal of Oral Maxillofacial Surgery. ;31(6) :670-4. Retrieved from https://doi.org/10.1054/ijom.2002.0260

Heydecke G, Boudrias P, Awad MA, De Albuquerque Jr RF, Lund JP, Feine JS. (2003) Within-subject comparisons of maxillary fixed and removable implant prostheses: patient satisfaction and choice of prosthesis. Clinical Oral Implants Research. ;14(1) :125-30. Retrieved from https://doi.org/10.1034/j.1600-0501.2003.140117.x

Heydecke G, Locker D, Awad MA, Lund JP, Feine JS. (2003) Oral and general healthrelated quality of life with conventional and implant dentures. Community Dentistry Oral Epidemiology. ;31(3) :161-8. Retrieved from https://doi.org/10.1034/j.1600-0528.2003.00029.x

Heydecke G, Tedesco LA, Kowalski C, Inglehart MR. (2004) Complete dentures and oral health- related quality of life-do cIRPing styles matter? Community Dentistry Oral Epidemiology. ;32(4) :297-306. Retrieved from https://doi.org/10.1111/j.1600-0528.2004.00169.x

Hyland R, Ellis J, Thomason M, El-Feky A, Moynihan P. (2009) A qualitative study on patient perspectives of how conventional and implant-supported dentures affect eating. Journal of Dentistry. ;37(9) :718-23. Retrieved from https://doi.org/10.1016/j.jdent.2009.05.028 
Kroll P, Hou L, Radaideh H, Sharifi N, Han PP, Mulligan R, et al. (2018) Oral healthrelated outcomes in edentulous patients treated with mandibular implantretained dentures versus complete dentures : systematic review with metaanalyses. Journal of Oral Implantology. ;44(4) :313-24. Retrieved from https://doi.org/10.1563/aaid-joi-D-17-00210

Köse 0, Alkurt M, Dilsiz A, Arabacı T. (2013) Dişsizliğin beslenme alışkanlıkları ve vücut ağırlığı üzerine etkileri. Atatürk Üniversitesi Diş Hekimliği Fakültesi Dergisi ;23(3) :399-407. Retrieved from https://dergipark.org.tr/en/pub/ataunidfd/issue/2466/31487

Locker D, Allen F. (2007) What do measures of 'oral health-related quality of life'measure ? Community Dentistry Oral Epidemiology. ;35(6) :401-11. Retrieved from https://doi.org/10.1111/j.1600-0528.2007.00418.x

Locker D, Matear D, Lawrence H. (2002) General health status and changes in chewing ability in older Canadians over seven years. Journal of Public Health Dentistry. ;62(2) :70-7. Retrieved from https://doi.org/10.1111/j.17527325.2002.tb03425.x

Locker D. (1988) Measuring oral health : à conceptual framework. Community Dental Health Journal. ;5(1) :3-18.

McGrath C, Bedi R. (2001) An evaluation of a new measure of oral health related quality of life- OHQoL-UK (W). Community Dental Health. ;18:138-43.

McGrath C, Bedi R. (2003) Measuring the impact of oral health on quality of life in Britain using OHQoL-UK. Journal of Public Health Dentistry. ;63(2) :73-7. Retrieved from https://doi.org/10.1111/j.1752-7325.2003.tb03478.x

Mumcu G, Inanc N, Ergun T, et al : (2006) Oral health related quality of life is affected by disease activity in Behcet's disease. Oral Dis ; $12: 145-151$. Retrieved from https://doi.org/10.1111/j.1601-0825.2005.01173.x

Nations. U. (2005) World pIRPulation to increase by 2.6 Billion over next 45 years, with all growth occuring in less develIRPed regions. [Available from : htCDs://www.un.org/press/en/2005/pIRP918.doc.htm.

Organization WH. (2007) International Classification of Functioning, Disability, and Health : Children \& Youth Version : ICF-CY : World Health Organization;.

Organization WH. (2017) Nursing and midwifery in the history of the World Health Organization 1948-2017.

Ozdemir AK, Ozdemir HD, Polat NT, Turgut M, Sezer H. (2006) The effect of personality type on denture satisfaction. International Journal of Prosthodontics. ;19(4):364-70.

Preciado A, Del Río J, Lynch CD, Castillo-Oyagüe R. (2013) A new, short, specific questionnaire (QoLIP-10) for evaluating the oral health-related quality of life of implant-retained overdenture and hybrid prosthesis wearers. Journal of Dentistry. ;41(9) :753-63. Retrieved from https://doi.org/10.1016/j.jdent.2013.06.014

Sadowsky SJ. (1997) The implant-supported prosthesis for the edentulous arch : design considerations. The Journal of Prosthetic Dentistry. ;78(1) :28-33. Retrieved from https://doi.org/10.1016/S0022-3913(97)70084-2

Slade GD, Spencer AJ. (1994) DevelIRPment and evaluation of the oral health impact profile. Community Dental Health. ;11(1) :3-11.

Slade GD : (1997) Derivation and validation of a short-form oral health impact profile. J Community Dent Oral Epidemiol ;25 :284-290. Retrieved from https://doi.org/10.1111/j.1600-0528.1997.tb00941.x 
Thomason JM, Feine J, Exley C, Moynihan P, Müller F, Naert I, et al. (2009) Mandibular two implant- supported overdentures as the first choice standard of care for edentulous patients-the York Consensus Statement. British Dental Journal ;207(4) :185-6. Retrieved from https://doi.org/10.1038/sj.bdj.2009.728

Tsakos G, Steele JG, Marcenes W, Walls AW, Sheiham A. (2006) Clinical correlates of oral health- related quality of life : evidence from a national sample of British older peIRPle. EurIRPean Journal of Oral Sciences. ;114(5):391-5. Retrieved from https://doi.org/10.1111/j.1600-0722.2006.00398.x

Walton JN, MacEntee MI. (2005) Choosing or refusing oral implants : a prospective study of edentulous volunteers for a clinical trial. International Journal of Prosthodontics. ;18(6).

Åstrøm A, Haugejorden O, Skaret E, Trovik T, Klock K. (2006) Oral impacts on daily performance in Norwegian adults : the influence of age, number of missing teeth, and socio-demographic factors. EurIRPean Journal of Oral Sciences. ;114(2) :115-21. Retrieved from https://doi.org/10.1111/j.16000722.2006.00336.x 